\title{
Electrical Storms after Levonorgestrel (Synthetic Progestin)-Releasing Intra-Vaginal Device Insertion. A Case Report and a Short Review of Literature
}

\author{
Sergio Fasullo ${ }^{*}$, Giorgio Maringhini ${ }^{1}$, Piero Fasullo², Filippo Ganci ${ }^{1}$, Arcangelo Giamporcaro, \\ Sebastiano Scalzo', Fernanda Pipitone', Vito Pinto', Graziella Vetrano', Gabriella Terrazzino1, \\ Stefania Davì ${ }^{3}$, Nicolò Renda ${ }^{4}$, Antonio Maiorana ${ }^{5}$
}

${ }^{1}$ Division of Cardiology “Paolo Borsellino”, G.F. Ingrassia Hospital, Palermo, Italy

${ }^{2}$ Operative Unit of Gynecology, S. Antonio Abate Hospital, Trapani, Italy

${ }^{3}$ Chemistry and Pharmaceutical Technologies, University of Palermo, Palermo, Italy

${ }^{4}$ Psychiatry, CTA La Rinascita, Palermo, Italy

${ }^{5}$ Operative Unit of Gynecology, ARNAS Civico, Palermo, Italy

Email: *sergio.fasullo72@gmail.com

How to cite this paper: Fasullo, S., Maringhini, G., Fasullo, P., Ganci, F., Giamporcaro, A., Scalzo, S., Pipitone, F., Pinto, V., Vetrano, G., Terrazzino, G., Davì, S., Renda, N. and Maiorana, A. (2018) Electrical Storms after Levonorgestrel (Synthetic Progestin)-Releasing Intra-Vaginal Device Insertion. A Case Report and a Short Review of Literature. Open Journal of Obstetrics and Gynecology, 8, 338-343. https://doi.org/10.4236/ojog.2018.84037

Received: January 30, 2018

Accepted: April 10, 2018

Published: April 13, 2018

Copyright $\odot 2018$ by authors and Scientific Research Publishing Inc. This work is licensed under the Creative Commons Attribution International License (CC BY 4.0).

http://creativecommons.org/licenses/by/4.0/

\begin{abstract}
We report a case of arrhythmic storm in a patient with recent vaginal insertion of a device with release of levonorgestrel (synthetic progestin). A woman of 60 years was hospitalized for runs of monomorphic sustained ventricular tachycardia. She received a vaginal device levonorgestrel-releasing 2 days before admission. No history of associated cardiovascular or thyroid disease or risk factors was reported. Laboratory parameters as well as ECG and echocardiogram were normal. After 48 hours from removal of the vaginal device, the patient was asymptomatic and showed only single ectopic beats, sometimes in pairs. The subsequent coronary angiography, electrophysiological study and cardiac magnetic resonance resulted negative.
\end{abstract}

\section{Keywords}

Levonorgestrel, Progesterone, Ventricular Arrhythmias

\section{Introduction}

The effect of sexual hormones on cardiovascular health is becoming a topic of interest among researchers, who are beginning to realize that the actions of synthetic progestin on heart function are dramatically different from those of natu- 
ral progesterone. In addition, women have slower cardiac repolarization than men, which manifests itself as longer heart rate corrected QT intervals (QTc) on the electrocardiogram (ECG) [1]. This sex difference is apparent only after puberty [2]. Furthermore, women are more prone than men to develop torsades de pointes (TdP) ventricular arrhythmias after administration of drugs prolonging cardiac repolarization (e.g., antiarrhythmic drugs, terfenadine, erythromycin, etc.) [3] [4] [5]. These findings suggest a role for sex hormones in the response to drugs that alter cardiac repolarization, and animal studies have demonstrated that sexhormones can alter potassium channel expression, ion currents, cardiac repolarization, and QT response to drugs [6] [7] [8] [9].

\section{Case Report}

We report a case of arrhythmic storm in a patient with recent vaginal insertion device with release of levonorgestrel (synthetic progestin). A 60 years-old woman went to the first aid of "G.F. Ingrassia Hospital, Palermo" due to heavy palpitations and general malaise. The ECG performed at the emergency department showed a run of monomorphic sustained ventricular tachycardia (VT), then during monitoring intermittent repeated VT storms with spontaneous cessation were evidenced. For this reason she was immediately hospitalized at the local intensive care cardiology unit (ICCU). The patient, in the course of anamnestic survey, reported that she was subjected to intervention by the application device vaginal the day before. She was not receiving other drugs, and no history of associated cardiovascular, thyroid or other disease was reported. In addition, no risk factor was present.

At the entry into the ICCU the patient presented palpitations and dizziness and these symptoms were concomitant with the presence of paroxysmal runs of sustained VT, sometimes with polymorphic characteristic. On admission the patient was haemodynamically stable with blood pressure $110 / 60 \mathrm{mmHg}$, normal oxygen saturation (94\%) in air room, and with normal values at the arterial blood gas evaluation ( $\mathrm{pH} 7.45, \mathrm{PO}_{2} 95 \mathrm{mmHg}, \mathrm{PCO}_{2} 39 \mathrm{mmHg}, \mathrm{HCO}_{3} 24.2$ $\mathrm{mmol} / \mathrm{l})$. In addition, plasma samples were also obtained to check laboratory parameters, which resulted in the normal range, especially ions such as $\mathrm{Na}^{+}, \mathrm{K}^{+}$, $\mathrm{Cl}^{-}, \mathrm{Mg}^{2+}, \mathrm{Ca}^{2+}$. These parameters were measured every $12 \mathrm{~h}$ for the first 24 hours, then every 24 hours. An echocardiogram, performed immediately after admission, do not show morphologic heart abnormalities. Just after, she received gynaecological consultation which led to the removal of the device. After this first evaluation, immediate beta blocker (metoprolol) treatment (first parenteral, then oral) has been established and, due to the persistence of the ventricular arrhythmias, continued amiodarone infusion was also added. Unfortunately this combination reduced but did not eliminate the episodes of VT. The control of thyroid hormones resulted in the normal range in plasma sample obtained before and after amiodarone treatment. Despite the timely removal of the device, the patient continued to be symptomatic for palpitation and to have arrhythmic 
storm. After $48 \mathrm{~h}$ of incessant and paroxysmal arrhythmic episodes the patient became progressively completely asymptomatic, sinus rhythm at ecg, and in the subsequent hours showed only single ectopic beats, sometimes in pairs at Holter exam. The third day the patient underwent coronary angiography that did not show any alteration. For this reason in the subsequent day she was transferred to another hospital to perform electrophysiological study and cardiac magnetic resonance. Both tests resulted negative, so the patient was discharged with the indication to continue the beta-blocker treatment.

Three months after she was hospitalized again in our department for 2 days, but no arrhythmic event was observed during monitoring and in the 48-hours ECG Holter test; also the echocardiogram was again normal (normal ventricular function), as well as the laboratory parameters, among which catecholamines (Adrenaline $42 \mathrm{ng} / \mathrm{L}$, Norepinephrine $335 \mathrm{ng} / \mathrm{L}$ ), aldosterone $(26 \mathrm{pg} / \mathrm{ml}$ ) and thyroid hormones (T3 1, 3 nmoli/l, TSH $0.65 \mathrm{mU} / \mathrm{L}$ ).

An informed content regarding anonymous data publication has been obtained from the patient.

\section{Discussion}

Probably, while synthetic progestin can cause coronary spasms and cardiac disease, natural progesterone can protect the heart. In postmenopausal women, higher blood levels of progesterone are associated with lower blood pressure increase and blood vessel constriction in response to angiotensin II. In a rodent study it was found that progesterone protects the heart from arrhythmias [10]. In addition, findings regarding the nongenomic effects of progesterone have been reported in various cells and tissues [8] [9], particularly in cardiac myocytes [10]. The biological experimental analysis, combined with a computational analysis of effects of progesterone on cardiac repolarization, provided a framework to understand the dynamic natures of $\mathrm{QT}$ interval and TdP risks in various hormonal states, particularly given the complex interaction with multiple factors, including sympathetic nervous system status, heart rate, QT-prolonging drugs, and gene mutations. It has been shown that sexual hormones may alter the myocardial repolarization [11] [12] [13] [14].

Therefore, it can be considered that hormone replacement therapy (HRT) leads to early after-depolarizations and consequently to VT by prolonging the QT interval. On the other hand, a study in which women receiving HRT for 3 months were separated into two groups-those given only estrogen and others given estrogen plus progesterone-showed that QT dispersion (QTd) did not change, while QT duration was prolonged in the group with only estrogen replacement. In the same study it was stated that QTd decreased in the group receiving estrogen plus progesterone [15]. As a result, it was stated that HRT including estrogen plus progesterone homogenized the QT duration and therefore decreased the QTd. Spatial homogenization of ventricular repolarization by progesterone may be explained by a direct and nongenomic action of progestagens on myocardial conduction velocities, as previously reported in neuronal 
tissue [16] [17]. This highlights the need to take into account synthetic progesterone, as well as estrogen, when evaluating hormonal effects on repolarization in women. It is possible that the synthetic progesterone did not have the beneficial actions of natural progesterone on ventricular repolarization, but, on the contrary, it may have estrogen-like effects on ventricular repolarization; a combination of these effects in a patient with an increase in sympathetic nervous system status might explain our case report. The intrauterine system of levonorgestrel, is a contraceptive device commonly used in clinical practice. In addition to providing effective contraception, it is also frequently used for treatment idiopathic menorrhagia and to protect the uterus from endometrial hyperplasia in estrogen replacement therapy [18]. Negative side effects associated with the implant include acne, menstrual disorders, pelvic pain, and ovarian cysts. Most of these symptoms can resolve spontaneously within several months [19]. No cases of ventricular arrhythmias or arrhythmic side effects are reported. The levonorgestrel-releasing intrauterine system (LNG-IUS) is a safe, effective and acceptable form of contraception used by over 150 million women worldwide [20].

The LNG-IUS is a safe and effective device which has been shown to be useful not only as a contraceptive, but as a tool which can be used for a variety of gynecologic conditions or disorders. However, the IUS is not without its side effects [21].

Unfortunately, to date no study exploring synthetic progesterone effects on ventricular repolarization exists, as well as no report was found regarding the association between synthetic progesterone and ventricular arrhythmias. Our hypothesis appears to be justified from the lack of effects on arrhythmic storms by intravenous administration of beta-blocker and amiodarone and their combination, and further from the spontaneous cessation of arrhythmias 48 hours from device removal.

\section{Conclusions}

The levonorgestrel released from device is at a higher concentration in the uterus than that in the systemic circulation. Thus, the side effects of levonorgestrel are usually local and mild.

We reported this case of ventricular arrhythmias possibly associated with the system, to raise the awareness of the side effects of levonorgestrel and emphasize the prompt treatment for the adverse reactions. Her symptoms have been improved after the removal of the device nonostamte the antiarrhythmic therapy practiced.

Therefore, attention should be paid to the arrhythmic side effects of the device for better management of symptoms and to prevent serious complications.

It is important to know the adverse effects when you treat a disease.

\section{Acknowledgements}

We thank all the nurses of the cardiology staff (in particular Mrs. Gabriella Vicari and Mrs. Gabriella Musso) for continued help in the most critical moments 
of charitable and Dr. Pietro Di Pasquale and Dr. Salvatore Paterna, for their suggestions.

I would like to express my gratitude for the patients, without whom the profession itself would have no reason to be.

\section{References}

[1] Stramba-Badiale, M., Locati, E.H., Martinelli, A., Courville, J. and Schwartz, P.J. (1997) Gender and the Relationship between Ventricular Repolarization and Cardiac Cycle Length during 24-h Holter Recordings. European Heart Journal, 18, 1000-1006. https://doi.org/10.1093/oxfordjournals.eurheartj.a015357

[2] Rautaharju, P.M., Zhou, S.H., Wong, S., et al. (1992) Sex Differences in the Evolution of the Electrocardiographic QT Interval with Age. Canadian Journal of Cardiology, 8, 690-695.

[3] Makkar, R.R., Fromm, B.S., Steinman, R.T., Meissner, M.D. and Lehmann, M.H. (1993) Female Gender as a Risk Factor for Torsades de Pointes Associated with Cardiovascular Drugs. JAMA, 270, 2590-2597. https://doi.org/10.1001/jama.1993.03510210076031

[4] Lehmann, M.H., Hardy, S., Archibald, D., Quart, B. and MacNeil, D.J. (1996) Sex Difference in Risk of Torsade de Pointes With d,l-Sotalol. Circulation, 94, 2535-2541. https://doi.org/10.1161/01.CIR.94.10.2535

[5] Drici, M.D., Knollmann, B.C., Wang, W. and Woosley, R.L. (1998) Cardiac Actions of Erythromycin: Influence of Female Sex. JAMA, 280, 1774-1776.

https://doi.org/10.1001/jama.280.20.1774

[6] Liu, X.K., Katchman, A., Drici, M.D., et al. (1998) Gender Difference in the Cycle Length-Dependent QT and Potassium Currents in Rabbits. Journal of Pharmacology and Experimental Therapeutics, 285, 672-679.

[7] Bai, C.X., Kurokawa, J., Tamagawa, M., Nakaya, H. and Furukawa, T. (2005) Nontranscriptional Regulation of Cardiac Repolarization Currents by Testosterone. Circulation, 112, 1701-1710. https://doi.org/10.1161/CIRCULATIONAHA.104.523217

[8] Ehring, G.R., Kerschbaum, H.H., Eder, C., et al. (1998) A Nongenomic Mechanism for Progesterone-Mediated Immunosuppression: Inhibition of $\mathrm{K}^{+}$Channels, $\mathrm{Ca}^{2+}$ Signaling, and Gene Expression in T Lymphocytes. Journal of Experimental Medicine, 188, 1593-1602. https://doi.org/10.1084/jem.188.9.1593

[9] Mendiberri, J., Rauschemberger, M.B., Selles, J. and Massheimer, V. (2006) Involvement of Phosphoinositide-3-Kinase and Phospholipase C Transduction Systems in the Non-Genomic Action of Progesterone in Vascular Tissue. International Journal of Biochemistry \& Cell Biology, 38, 288-296. https://doi.org/10.1016/j.biocel.2005.09.012

[10] Nakamura, H., Kurokawa, J., Bai, C.X., et al. (2007) Progesterone Regulates Cardiac Repolarization through a Nongenomic Pathway. An In Vitro Patch-Clamp and Computational Modeling Study. Circulation, 116, 2913-2922. https://doi.org/10.1161/CIRCULATIONAHA.107.702407

[11] Gimeno, A.L., Gimeno, M.F. and Webb, J.L. (1963) Actions of Sex Steroids on the Electrical and Mechanical Properties of Rat Atrium. American Journal of Physiology, 205, 198-200. https://doi.org/10.1152/ajplegacy.1963.205.1.198

[12] Prinzmetal, M., Ishikawa, K., Nakashima, M., et al. (1967) Estrogens and the Heart. American Journal of Obstetrics \& Gynecology, 98, 575-576. 
https://doi.org/10.1016/0002-9378(67)90114-7

[13] Pragnell, M., Snay, K.J., Trimmer, J.S., et al. (1990) Estrogen Induction of a Small, Putative $\mathrm{K}^{+}$Channel mRNA in Rat Uterus. Neuron, 4, 807-812. https://doi.org/10.1016/0896-6273(90)90207-V

[14] Drici, M.D., Burklow, T.R., Haridasse, V., Glazer, R.I. and Woosley, R.L. (1996) Sex Hormones Prolong the QT Interval and Downregulate Potassium Channel Expression in the Rabbit Heart. Circulation, 94, 1471-1474. https://doi.org/10.1161/01.CIR.94.6.1471

[15] Haseroth, K., Seyffart, K., Wehling, M. and Christ, M. (2000) Effects of Progestin-Estrogen Replacement Therapy on QT-Dispersion in Postmenopausal Women. International Journal of Cardiology, 75, 161-165. https://doi.org/10.1016/S0167-5273(00)00317-X

[16] Christ, M., Haseroth, K., Falkenstein, E. and Wehling, M. (1999) Nongenomic Steroid Actions: Fact or Fantasy? Vitamins and Hormones, 57, 325-373. https://doi.org/10.1016/S0083-6729(08)60647-0

[17] Altunkeser, B.B., Özdemir, K., Îçli, A., Çelik, C., Akyürek, C. and Gök, H. (2002) Effects of Long-Term Hormone Replacement Therapy on QT and Corrected QT Dispersion during Resting and Peak Exercise Electrocardiography in Post-Menopausal Women. Japanese Heart Journal, 43, 1-7. https://doi.org/10.1536/jhj.43.1

[18] Varma, R., Sinha, D. and Gupta, J.K. (2006) Non-Contraceptive Uses of Levonorgestrel-Releasing Hormonal System (LNG-IUS): Survey and Systematic Overview. The European Journal of Obstetrics \& Gynecology and Reproductive Biology, 125, 9-28. https://doi.org/10.1016/j.ejogrb.2005.10.029

[19] Rauramo, I., Elo, I. and Istre, O. (2004) Long-Term Treatment of Menorrhagia with Levonorgestrel Intrauterine System versus Endometrial Resection. Obstetrics \& Gynecology, 104, 1314-1321. https://doi.org/10.1097/01.AOG.0000143824.16435.91

[20] Beatty, M.N. and Blumenthal, P.D. (2009) The Levonorgestrel-Releasing Intrauterine System: Safety, Efficacy, and Patient Acceptability. Therapeutics and Clinical Risk Management, 5, 561-574.

[21] Baldaszti, E., Wimmer-Puchinger, B. and Löschke, K. (2003) Acceptability of the Long-Term Contraceptive Levonorgestrel-Releasing Intrauterine System (Mirena): A 3-Year Follow-Up Study. Contraception, 67, 87-91. https://doi.org/10.1016/S0010-7824(02)00482-1 